\title{
ACERCA DE LA SUSTENTABILIDAD Y LA RACIONALIDAD AMBIENTAL: EL DIÁLOGO COMO FUENTE DE CAMBIO EN LA ACCIÓN EMPRESARIAL*
}

\author{
MARTA ELIANA GÓMEZ SANTRICH** * JUAN CAMILO LEÓN SAAVEDRA*** \\ UNIVERSIDAD COOPERATIVA DE COLOMBIA
}

Recibido/ Received/ Recebido: 16/05/2012 - Aceptado/ Accepted / Aprovado: 09/11/2012

\section{Resumen}

\begin{abstract}
En este documento se presenta una reflexión teórica sobre el discurso de la sostenibilidad fundamentado en la racionalidad económica. Dada la problemática ambiental esta visión no solo es limitada sino que agrava la situación, es por eso que analizamos dos conceptos que se contraponen a este discurso, la sustentabilidad como discurso que considera lo cultural, lo político, lo social y lo económico; y la racionalidad ambiental, como base para constituir un nuevo pensamiento promotor del cambio en la acción empresarial fruto de la comunión entre individuos. El concepto de cambio organizacional se estudia como eje articulador entre la sustentabilidad y la racionalidad ambiental. Las reflexiones de las que se ocupa este artículo se inscriben en el enfoque cualitativo, en cuanto a los medios empleados, se utilizó la revisión documental, a través de la cual se identificaron las fuentes escritas que abordaban las perspectivas teóricas y conceptos articuladores de este documento.

Palabras clave: Sustentabilidad, Racionalidad ambiental, Diálogo, Responsabilidad social, Cambio, Cambio organizacional.

\section{ABOUT SUSTAINABILITY AND ENVIRONMENTAL RATIONALITY: THE DIALOGUE AS A SOURCE OF CHANGE IN ENTREPRENEURIAL ACTION}

\begin{abstract}
This study presents a theoretical reflection about the sustainability speech based on economic rationality. Given the environmental problematic this view is not only limited but exacerbates this situation, this is why we analyze two concepts that contradict this speech, the sustainability as speech used in culture, politics, social and economic, and the environmental rationality, as the base to constitute a new thought which promotes changing in entrepreneurialaction product of acloseness among individuals. The concept of organizational change is studied as an articulator axis between sustainability and environmental rationality. The reflections presented in this article are qualitative. The tools used were documental review through which there were identified the written sources that treated theoretical perspectives and articulating concepts of this document.

Keywords: Sustainability, Environmental rationality, Dialogue, Social responsibility, Change, Organizational change.
\end{abstract}

Artículo de reflexión teórica de los proyectos de investigación "La importancia de las variables ambientales en los procesos de toma de decisiones en las organizaciones empresariales" y "Responsabilidad Social Universitaria para la Universidad Cooperativa de Colombia para el fortalecimiento de sus relaciones con los stakeholders" que se desarrollan con apoyo del Comité Nacional para el Desarrollo de la Investigación CONADI de la Universidad Cooperativa de Colombia.

* Contadora Pública -Universidad Cooperativa de Colombia, Candidata a Msc en Administración, Universidad Nacional de Colombia. Miembro del grupo de Investigación Contabilidad y Entorno Social. Decana de la Facultad de Ciencias Administrativas, Económicas y Contables de la Universidad Cooperativa, Sede Santa Marta. Correo Electrónico: martae.gomez@ucc.edu.co

**** Contador Público -Universidad Nacional de Colombia, Candidato a Msc en Administración, Universidad Nacional de Colombia. Miembro del grupo Contabilidad y Entorno Social. Docente instructor de la Universidad Cooperativa de Colombia, Sede Bogotá. Correo Electrónico: juan.leon@campusucc.edu.co 


\title{
A RESPEITO DA SUSTENTABILIDADE E DA RACIONALIDADE AMBIENTAL: O DIÁLOGO COMO FONTE DE MUDANÇA NA AÇÃO EMPRESARIAL
}

\begin{abstract}
Resumo
Neste documento se apresenta uma reflexão teórica sobre o discurso da sustentabilidade fundamentado na racionalidade econômica. Dada a problemática ambiental, esta visão não só é limitada mas também agrava a situação. É por isso que analisamos dois conceitos que se contrapõem a este discurso: a sustentabilidade como discurso que considera o cultural, o político, o social e o econômico; e a racionalidade ambiental, como base para constituir um novo pensamento promotor da mudança na ação empresarial, fruto da comunhão entre indivíduos. O conceito de mudança organizacional se estuda como eixo articulador entre a sustentabilidade e a racionalidade ambiental. As reflexões das quais se ocupa este artigo se inscrevem no enfoque qualitativo. Utilizou-se como metodologia a revisão documental, através da qual se identificaram as fontes escritas que abordavam as perspectivas teóricas e conceitos articuladores deste documento.

Palavras chave: Sustentabilidade, Racionalidade ambiental, Diálogo, Responsabilidade social, Mudança, Mudança organizacional.

Gómez, M. \& León, J. (2012) Acerca de la sustentabilidad y la racionalidad ambiental. El diálogo como fuente de cambio en la acción empresarial En: Revista de la Facultad de Ciencias Económicas de la Universidad Militar Nueva Granada. rev.fac.cienc.econ, XX (2).

JEL: M10, Q01, Q56.
\end{abstract}

\section{Introducción}

Uno de los componentes de la tan debatida responsabilidad social empresarial, es el ambiente, desde hace varias décadas ha comenzado a hacer parte de la agenda global por los impactos que el ser humano ha generado sobre él, y que afectan cada vez de manera más visible su cotidianidad.

La preocupación por los impactos ambientales ha llevado a organizaciones internacionales a plantear conceptos globales como el desarrollo sostenible que pretende garantizar la continuidad de la especie humana y de la tierra en sí misma, sin embargo, este tema se ha convertido en parte de la retórica instrumentalista que no busca el cambio en el modelo de desarrollo para una sociedad de largo plazo, sin dejarnos claro cuál es el objetivo del mismo y la forma como se logrará, lo cierto es que estamos asistiendo a un reverdecimiento de conciencias.

A pesar de esto, la percepción general de la problemática ambiental tiende a categorizarse solo desde lo ecológico obviando factores importantes en esa problemática, como lo cultural, lo social, la justicia y el reconocimiento del otro. Estos cuestionamientos reclaman una visión más amplia de ambiente, para este caso, lo entenderemos como el todo complejo que nos rodea y del cual hacemos parte.

Desde un análisis microeconómico, las empresas tienen responsabilidad en esta problemática, la razón está fundamentada en sus supuestos de funcionamiento en aras de lograr el objetivo básico de "maximizar el valor de la empresa". Esos supuestos promueven la toma de decisiones basados en el egoísmo y la individualidad, han afectado el reconocimiento del otro y esto ha causado los excesos en los actos humanos que terminan afectando al medio ambiente. Así "Al principio los incumplimientos fueron leves: simplemente llevar ropa y construir casas. Luego comenzamos a poner nuestras presas en manadas y a cultivar nuestros alimentos favoritos (...) Consecuencias de ese crecimiento de nuestro número y del desarrollo de nuestra capacidad de descolocar (...) La contaminación es siempre una cuestión de cantidades" (Lovelock, 1991, 153-155). 
Son estos excesos la génesis del problema, no es la misma existencia humana, porque antes la naturaleza podía cargar nuestros efectos de las acciones de sobrevivencia, estaba en la capacidad de recuperar el uso que hacíamos de ella, de esta manera "La naturaleza no era objeto de la responsabilidad humana; ella cuidaba de sí misma y cuidaba también, con la persuasión y el acoso pertinente, del hombre" (Jonás, 1994, 28).

Si bien el origen de estos excesos no se pueden atribuir únicamente a la aparición del capitalismo o su consolidación a través de la segunda revolución industrial, si es claro que esto agravó la situación y cambió la relación entre el hombre y su medio ambiente, más aún cuando en el siglo XX los economistas neoclásicos enfatizaron en la racionalidad económica como la base de la toma de decisiones para garantizar la maximización de beneficios y la optimización de costos, bajo esta racionalidad se fortalece la instrumentalización del todo al objetivo particular económico y por esto no sólo se habla de la transformación de la naturaleza a un recurso más, sino del rechazo a lo realizado, la externalidad aparece como el argumento perfecto para justificar las decisiones empresariales, según las cuales los problemas son de otros.

De manera preocupante son los impactos evidentes ocasionados por esta manera de actuar y la necesidad de un cambio ante una inminente autodestrucción, lo que nos ha llevado a repensar, a reflexionar, sobre el comportamiento que hasta ahora ha tenido el hombre, ¿qué podemos hacer?

Es desde el desarrollo sustentable y la racionalidad ambiental, donde la problemática reconoce una crisis del conocimiento. En este artículo pretendemos analizar estas propuestas y situarnos luego en las empresas por tener gran parte de responsabilidad, creemos que es una reflexión necesaria y para muchos idealista, pero se plantea con el fin de buscar la bondad en los actos así, "El uso del término bien remite obligadamente algo que transciende el nivel empírico del ejercicio de las acciones; esto es, a un ideal. Los ideales son la fuente de validez con base en la cual el tribunal de la razón juzga en su íntima dignidad la bondad incondicionada de una actuación" (Uribe, 2005, 8).
Las reflexiones de las que se ocupa este documento se inscriben en el enfoque cualitativo en tanto este permite un abordaje más profundo de las problemáticas que se generan en el ámbito de la gestión (Gummenson, 2000) y se constituye en "un modo de encarar el mundo de la interioridad de los sujetos sociales y de las relaciones que es establecen con los contextos y otros actores sociales" (Galeano, 2004, 16), razón por la cual se auscultan los argumentos teóricos que fundamentan los conceptos de: desarrollo sostenible, sustentabilidad y racionalidad ambiental.

En cuanto a los medios empleados para el desarrollo de estas reflexiones, se utilizó la revisión documental, a través de la cual se identificaron en orden de importancia las fuentes escritas que abordaban las perspectivas teóricas y conceptos articuladores de este documento.

Esta reflexión se compone de cinco partes: en primer lugar abordamos desde un enfoque crítico los conceptos de desarrollo sostenible y sustentabilidad desde múltiples visiones que además de exponer su ambigüedad, ponen de manifiesto su complejidad y complementariedad; en segundo lugar hacemos un acercamiento a los procesos de cambio tanto a nivel humano como organizacional; en tercer lugar nos ocupamos de la racionalidad económica y la racionalidad ambiental, como los detonadores que impulsan las acciones que promueven diversas paradigmas de desarrollo sostenible y sustentabilidad; en cuarto lugar, se plantean algunas reflexiones sobre la empresa socialmente responsable; y finalmente, se proponen interrogantes que invitan al debate de la comunidad académica.

\section{El desarrollo sostenible}

Los antecedentes del desarrollo sostenible podrían remontarse a la década de los setenta, cuando en Estocolmo en el marco de la conferencia sobre medio ambiente el tema es visto desde una óptica general y se plantea la finitud del desarrollo; se vislumbra "el desarrollo" como una forma de pensamiento que estaba llegando a su fin; se cuestionan los dos presupuestos fundamentales de la promesa del desarrollo: en primer lugar, la promesa de que el desarrollo po- 
día ser universalizado en el espacio, y segundo, que sería durable en el tiempo.

Es a partir del reconocimiento de la finitud de los recursos naturales, que se plantea la idea del desarrollo sostenible; sin embargo, desde que el concepto aparece por primera vez en 1987 publicado en el Informe Brundtland definido como aquel que busca "satisfacer nuestras necesidades actuales sin comprometer la capacidad de las generaciones futuras para satisfacer las suyas" la característica más prominente en esta definición es su rebosante ambigüedad, lo cual hace que algunos de sus intentos de aplicación desvirtúen los objetivos para los cuales fue pensado.

Colocar el adjetivo de sostenible al lado del desarrollo, parece reforzar la idea no de un desarrollo sino de un crecimiento, infinito y desigual, muy amplia es también la manera acrítica con la que algunas veces son pronunciados e instrumentalizados estos términos; es aquí donde se ancla parte de la discusión, al respecto Ángel (1996a, 114) manifiesta "desde el punto de vista lingüístico, estos tres términos tienen connotaciones distintas. Sostenido, es lo que se sostiene por si mismo, o sea, aquello que ha llegado a un equilibrio que permite la prolongación de la estructura. Tal es el caso del ecosistema. Sostenible, se refiere a algo que -tiene que ser sostenido-". Se refiere, por tanto a un sistema en desequilibrio que exige inducciones externas para lograr la sostenibilidad.

Las contradicciones entre estos dos términos se afianzan, por ejemplo en la medida en que se entienda el desarrollo como sinónimo de crecimiento; sin embargo, si damos al desarrollo un contenido y un significado como el planteado por Gallopin (2003, 21) "la palabra "desarrollo" apunta claramente a la idea de cambio, cambio gradual y direccional" o lo manifestado por Reachman "aspiramos a un desarrollo en equilibrio dinámico, autocentrado, racionalmente planificado y en la medida de lo posible basado en la imitación de la economía natural de los ecosistemas" (Herrero, 2005, 27), las contradicciones y ambigüedades pierden fuerza e importancia.

Sin embargo, estas contradicciones y ambigüedades parecen ser aceptadas por la mayoría y algunas de las razones para ello las plantea Gligo $(2006,14)$ :
"Se le acepta porque, inconsciente o conscientemente, deja en la penumbra las numerosas interrogantes y contradicciones derivadas del tránsito abstracción-concreción de las definiciones sobre desarrollo. Permite disfrazar la realidad y verificar, cuantificar y contrastar como se avanza hacia objetivos de "mayor bienestar", aunque las cifras estén mostrando lo contrario."

\subsection{Paradigmas y posturas sobre desarrollo sostenible y sustentabilidad}

La sustentabilidad constituye el principal pretexto para realizar cuestionamientos no sólo al estilo de desarrollo, sino a los valores, cosmovisiones y/o paradigmas dominantes (Elizalde, 2007, 53), y esta es una idea, quizás previa a la de desarrollo sostenible, sin embargo en la actualidad, parecen utilizarse indistintamente, haciendo precisión más que en el término, en el contenido del discurso.

Para Elizalde $(2007,54)$ la sustentabilidad es complementaria al desarrollo, "el desarrollo dice relación con el despliegue de la potencialidad contenida internamente en un fenómeno, pero dicho fenómeno se despliega, no en un vacío, sino en un ambiente o ecosistema. La sustentabilidad dice, relación con el contexto necesario para el despliegue del potencial del desarrollo, pero dicho desarrollo puede ser destructor o potenciador del medio que lo sustenta"; se plantea entonces una dinámica compleja del desarrollo, en la que a la vez que orientándose a él, el sujeto del desarrollo se auto-modifica, tratando de adaptarse a ese medio, este sufre también una transformación; el desarrollo es a la vez, producto y productor del medio que lo sustenta.

Otra perspectiva es el paradigma ecológico superficial, se enmarca dentro de las ideas económicas dominantes, hace un reconocimiento a la necesidad de pensar en generaciones venideras, $y$ por tanto plantea también la necesidad de realizar algunos cambios, sin embargo, estos son propuestos desde las teorías económicas dominantes, que tienden a favorecer y equiparar el crecimiento económico con el desarrollo. Las alternativas desde este paradigma van desde el uso racional de los recursos hasta la utilización de fuentes alternativas de energía (He- 
rrero, 2005, 22); no se cuestiona la esencia de las relaciones económicas, básicamente se plantea una interiorización de la problemática ambiental a la luz de lo predominante en el ámbito económico.

Lo planteado por este paradigma, casi que no tiene relación con las nociones de sustentabilidad de Elizalde, en tanto se inscribe en un marco de sustentabilidad débil, definida por Gallopin $(2003,13)$ como aquella en la que "el sistema que importa es la economía, y la naturaleza se relega a su función proveedora de recursos y servicios naturales y la de sumidero de los desechos generados por la actividad humana".

El paradigma ecológico o de ecología profunda, se va al otro extremo, a la conservación de lo natural, por encima de los demás factores, esta visión reclama una reorganización de las relaciones sociales, a partir de lo ecológico; es decir, reconocer relaciones $e$ interdependencias. Uno de los puntos para resaltar en este paradigma es el valor a la vida, a cualquier tipo de vida, con lo que equipara al ser humano con todas las especies vivientes, en aras de promover relaciones más justas y equitativas.

El desarrollo humano sostenible, se vislumbra como enfoque integrador y conciliador, se pretende conservar tanto lo humano como lo natural. Desde esta perspectiva el desarrollo sostenible "es modelo de desarrollo integral, endógeno, perdurable y humano, que tiene como fin supremo la defensa de la naturaleza y de la especie humana, y que otorga un papel protagónico a los principios de la diversidad y solidaridad, del mismo modo que persigue preservar el patrimonio biológico y cultural de los pueblos, en sus dimensiones local, regional, nacional y global" (Herrero, 2005, 24).

Esta visión de desarrollo sostenible tiene varias particularidades, en primer lugar plantea el desarrollo como un proceso endógeno, en el que cada país tendría que considerar de acuerdo a sus características, la forma de propender por su desarrollo, deja de lado la idea del desarrollo preconcebido como algo deseable y alcanzable, para plantearlo como una mirada hacia adentro que permitiría configurar, un estilo de desarrollo.
Estas dimensiones se encuentran inevitablemente conectadas, por lo que el descuidar alguna de ellas, afecta directamente el desarrollo de la otra; se convierte el desarrollo sostenible desde esta perspectiva, en un concepto complejo, que comprende un sinnúmero de elementos inmersos en cada una de estas dimensiones, que se recomponen en un todo, que superaría las limitaciones de pensar cada parte por separado, como lo plantean algunas de las visiones de desarrollo sostenible, abordadas en párrafos anteriores.

\subsection{La necesidad del cambio}

El desarrollo sostenible o sustentable se ha constituido en una referencia obligada en el discurso de lo político, social y empresarial, en parte se ha convertido en una moda; esta masificación del discurso ha generado que este pierda en parte su potencialidad transformadora de lo real, en tanto se convierte en un instrumento de la retórica.

La actual crisis ambiental fundamentada en la falta de preocupación por el futuro natural y social del mundo, podría ser también la oportunidad de generar cambios profundos en la sociedad, modificar estilos de vida y repensar nuestras formas de ver la realidad.

"La crisis ambiental es la manifestación de una crisis más profunda, la crisis de sentido que hoy está viviendo la humanidad" (Elizalde, 2007, 61); esa crisis de sentido está permeada por nuestras formas de ver y percibir la realidad, hace referencia a nuestras visiones, experiencias, paradigmas; se requieren entonces, cambios en los fundamentos de nuestras percepciones, es común, que algunos fenómenos ocurran frente a nosotros, y no nos percatamos de ellos, sencillamente, no existen para nosotros.

Dicha crisis de sentido tiene raíces en una crisis moral, de principios, de nuestros valores, emociones, actuaciones, etc., por lo que según Elizalde (2007, 61) "el problema que hoy enfrenta la humanidad es primordialmente algo así como un subdesarrollo moral, ya que hemos alcanzado un impresionante desarrollo científico y tecnológico que nos da el poder de modificar e incluso destruir la naturaleza y a 
nosotros mismos (...) somos niños al mando de una locomotora" .

Las posibilidades de un desarrollo sostenible requieren transformaciones profundas en el seno de la humanidad, en nuestras formas de conocer, de percibir, una revisión critica de nuestro valores, de nuestra percepción de lo humano; se requiere un cambio estructural de nuestra formas de conocimiento, una revolución del pensamiento. Estas transformaciones deberán plantearse tanto a nivel del hombre como ser humano como del hombre como parte integrante y fundante de las organizaciones.

\section{Un acercamiento al cambio}

\subsection{Algunas concepciones sobre el cambio}

Comprender el papel del hombre en los procesos de cambio implica, en primer lugar una aproximación al concepto de cambio mismo, pues lejos de las concepciones comunes y tradicionales que plantean el cambio como modificaciones aparentes, los procesos de cambio implican modificaciones en las estructuras de las organizaciones, y por lo tanto se plantean desde diversas concepciones de organización, permeando el papel del hombre-ser humano como piedra angular de las mismas.

Es común afirmar que los procesos de cambio son difíciles, poco probables y con pocas posibilidades de éxito; sobretodo cuando se trata de cambios con respecto de la cultura, la cual "evoluciona sin control social sobre la misma, esto es, que la cultura a pesar de ser un producto humano no es controlado por la humanidad ni por ninguna de sus partes. En consecuencia, hay razones para creer que los cambios no ocurrirán de la manera ni en el momento adecuados" (Márquez, 2002, 7); lo anterior, aunque parece una visión pesimista, pone de manifiesto lo complejo del papel del hombre en el cambio.

Desde perspectivas más orientadas a la gestión, el cambio es entendido como "una transformación de características, una alteración de dimensiones o aspectos más o menos significativos" (Montealegre, 2006, 39), implicando en todo caso un movimiento desde unas condiciones existentes hacia otras deseables, o que podrían considerarse mas eficientes.
Ahora bien, el desarrollo de los procesos de cambio organizacional, implica también un reconocimiento del concepto de organización y de lo humano en la organización. En este sentido, para Mcgregor, Simón \& Bernard citados por Cruz (2000, 130), "una organización es un sistema de comportamientos sociales interrelacionados, de aquellas personas que la integran o son miembros de ella", mientras para Bradford citado por Cruz (2000, 131), las organizaciones, así como los individuos y los grupos, son sistemas dinámicos que requieren ajustes y adaptaciones a los permanentes cambios que se producen y a los cuales ellas (ellos) deben responder prontamente.

El ser humano se convierte en el principal agente de cambio en la organización, en la medida en que el actuar de la misma represente sus propios intereses o los de su grupo, o de alguna manera se detonen como un incentivo que propenda por la cohesión en la organización así como por la supervivencia de la misma, más adelante se tratará este tema.

\subsection{El cambio en las organizaciones}

El cambio organizacional se ha entendido como la adaptación de las organizaciones a las presiones o influencias del entorno en el que se desenvuelven, sin embargo, esta afirmación parecería simple al tratar de explicar cómo y por qué cambian o no las organizaciones.

Son identificables tres concepciones: "la primera, se aborda considerando la visión que adopta la toma de decisiones y por ende el cambio como un proceso racional y controlado; la segunda, está asociada a la teoría de sistemas, que asume el cambio organizacional como resultado de fuerzas ambientales $y$, la tercera, se ubica desde la perspectiva de la auto-organización, la cual llevaría a entender el cambio como un asunto de capacidades internas pero también de situaciones emergentes bajo un modelo de sistema con lógica propia" (Valdés, 2008). Se ahondará de aquí en adelante en las dos últimas concepciones y se plantearan algunos elementos a partir del neoinstitucionalismo sociológico.

El cambio desde la teoría general de los sistemas, también conocido como visión de adaptación, parte 
de lo planteado por Morgan (1995, 38), quien afirma que "las organizaciones son sistemas abiertos que necesitan gestionar cuidadosamente, satisfacer y equilibrar sus necesidades internas y adaptarse a las circunstancias ambientales o del entorno".

"Las organizaciones tienen capacidad de "adaptación" a su medio social donde se desenvuelven, consistiendo este acople en realizar modificaciones internas (estructura, tecnología, sistema de dirección, cultura, etc.) de acuerdo con las percepciones de sus miembros. Por esta razón, el cambio (y las decisiones) dependerían más de las demandas externas o de otros sistemas sociales, que de la propia dinámica interna organizacional" (Váldez, 2008).

Por otra parte, el cambio desde la perspectiva de la auto-organización toma como referencia las ideas de Etkin \& Schvarstein $(1995,61)$ acerca de la identidad de las organizaciones, una visión compleja de la organización, que puede entenderse como "una estructura de significados y sus estados internos no son dependientes de la presión de factores impersonales que la modelen. Son los participantes quienes atribuyen sentido a las presiones de otros miembros $y$ del contexto".

El cambio organizacional se produce desde dentro, desde los rasgos de identidad de la organización, no se resume al proceso de adaptación, que se "entiende como un proceso que ocurre en el nivel de lo estructural; no afecta los rasgos de identidad" (Etkin \& Schvarstein, 1995, 108).

Desde los planteamientos del neoinstitucionalismo sociológico, las organizaciones son entidades sociales, insertas en complejas redes de creencias, esquemas culturales y convenciones que modelan sus objetivos y prácticas. Estas reglas y creencias que constituyen las instituciones se trasladan al interior de las organizaciones ${ }^{1}$ a través de tres procesos de isomorfismo institucional, los cuales pueden ser: isomorfismo coactivo, normativo y mimético (DiMaggio \& Powell, 1993, citados por Araujo, 2003, 699).
En cuanto al isomorfismo coactivo, hace referencia a las presiones que generan las organizaciones a otras organizaciones en una relación de dependencia en la que una tiene el derecho o poder legitimo para imponer el cumplimiento o acatamiento de una directriz (casa matriz- subsidiaria, $\mathrm{PE}$ ), en el tema del que se ocupa este escrito, valdría la pena resaltar que las organizaciones que se dedican a la explotación de recursos naturales en su mayoría, manejan figuras de multinacionales, por lo que el isomorfismo coactivo, es viable y tal vez muy aplicable para estas organizaciones (Araujo, 2003).

$\mathrm{El}$ isomorfismo normativo, se refiere al cumplimiento de normas y procedimientos sociales y profesionales; es decir, incluye lo determinado por los órganos que rigen la profesión, como las entidades que de una u otra manera regulan el proceso de formación del profesional (Ministerio de Educación, ICFES). Por otra parte, el isomorfismo mimético; se refiere a los procesos en los que las organizaciones imitan las acciones exitosas realizadas por otras organizaciones para enfrentar los cambios del contexto institucional (Araujo, 2003).

Por otra parte, Alvarado (2006) revisando la perspectiva institucional, establece cuatro categorías que agrupan algunas concepciones de cambio organizacional:

"El cambio ligado a poder e intereses: Las presiones de los grupos de interés poseen suficiente poder para introducir modificaciones en el ambiente institucional, al que la organización debe adaptarse de manera recurrente. La organización guía su accionar por medio de valores, normas y actitudes que retoma de su medio, intentando que estas ideas le permitan preservar el poder y los intereses de sus dirigentes" (Selznick, 1949 citado por Alvarado, 2006).

En el mismo sentido, Powell \& DiMaggio (2001) sostienen que "el cambio ligado a legitimidad e isomorfismo: La organización interactúa con el ambiente pleno de creencias de donde se derivan reglas y

Este proceso de traslado o internalización que las organizaciones hacen de las instituciones, es lo que se considera como el proceso que va del cambio institucional al cambio organizacional. 
prácticas que se asumen como la forma apropiada de realización de las labores organizativas. Se propone que la estructura en las organizaciones sea homogénea entre aquellas de un mismo campo o sector". En el concepto de Alvarado, estos acuerdos institucionales no solo limitan las opciones de decisión y acción, sino que también establecen los criterios mediante los cuales las personas descubren sus preferencias, por lo que se ven impedidos para reconocer o actuar a favor de sus intereses.

"La reintroducción del poder e intereses en el análisis del cambio: La construcción de la visión del cambio conlleva a la atención sobre el poder y el interés a partir de cuatro etapas particulares: innovación, rutinización, objetivación y sedimentación" (Alvarado, 2006).

Por otro lado, el cambio ligado a riesgo e incertidumbre según Kondra \& Hinings (1998) citados por Alvarado (2006), hace referencia al isomorfismo, es decir, como las formas y prácticas iguales corresponden a un desempeño similar, cuya conducta debe estar orientada al riesgo, donde aquellas organizaciones que hagan caso omiso de algunas limitaciones importantes impuestas por el accionar y el pensamiento organizacional, ese alejamiento de las normas puede brindar oportunidades competitivas. La incertidumbre dentro de una organización es un factor de presión para la realización de ajustes pertinentes, por lo que se está dispuesto a correr riesgos que permiten obtener un desempeño sobresaliente, convirtiéndose en un nuevo modelo a seguir, impulsando de esta manera procesos de cambio en el resto de organizaciones.

Son diversas las concepciones alrededor del cambio organizacional, sin embargo, al momento de estudiar su relación con lo ambiental y lo humano, son las propuestas provenientes de las teorías neoinstitucionalistas, las que a partir del análisis organizacional, muestran un panorama alentador para estudiar el papel de humano en los procesos de cambio.

El cambio organizacional "es un proceso de creación colectiva a través del cual los miembros de una determinada colectividad aprenden juntos, es decir, inventan y determinan nuevas formas de jugar el juego social de la cooperación y del conflicto (una nueva praxis social), y adquieren capacidades cognoscitivas, de relación y organizativas correspondientes" (Rosas, 2008, 198).

A continuación se plantean argumentos para el cambio desde la perspectiva individual como organizacional para el reconocimiento y superación de las problemáticas hasta aquí planteadas.

\section{Racionalidad económica y racionalidad ambiental}

El problema como se ha analizado, no está en el mejor adjetivo que debe acompañar la palabra desarrollo, el reto está en el cambio en la forma como pensamos y allí la noción de racionalidad ambiental toma importancia como alternativa para el cambio.

El origen de la problemática ambiental que estamos presenciando en este tiempo, no es fruto del capitalismo sino de los cambios que surgieron en nuestra forma de ver el mundo, cuando se nos ocurrió pensar que el centro del universo era el hombre. En consecuencia, los tres factores críticos para el cambio de pensamiento respecto al medio ambiente son: los deseos de "supervivencia", la muerte y la individualidad.

El deseo de "supervivir" va más allá de la satisfacción de necesidades básicas y se dirige hacia el aumento de bienestar a partir de la riqueza patrimonial, tanto así, que la historia ha demostrado que el poder está amarrado a la tenencia de dinero.

Antes el humano buscaba sobrevivir, los problemas ambientales no empezaron necesariamente con la contaminación provocada por la revolución industrial o del aumento del uso de recursos para el aprovechamiento de las máquinas, la misma incapacidad del humano de adaptarse a su medio desde el paleolítico, generó impactos de desequilibrio forzado en el ambiente, la caza no sólo para el mantenimiento de una dieta definida en la prehistoria sino también como protección de las bajas temperaturas con pieles de animales, se constituyo en una de las primeras afectaciones humanas a la tierra, tal como lo plantea Ángel (1996b, 14): "la caza se va haciendo más 
selectiva y el número de víctimas crece significativamente. Los restos de los cien mil caballos encontrados en Solutré (Dordogne) o de los mil mamuts de Predmost, representan ya una especie de ecocidio".

Dichos desequilibrios de los primeros humanos podían ser resistidos por la naturaleza, su capacidad de renovación era superior a la capacidad de depredación humana, sin embargo cuando se pasa del sobrevivir al "supervivir", los desequilibrios no pueden ser asumidos en los procesos de renovación naturales y así el problema empieza a hacerse evidente.

El segundo factor es la muerte; antes los humanos no temían morir, la tradición religiosa católica que permeaba la sociedad en todos sus ámbitos había enseñado que había vida eterna, los sufrimientos y la humildad con la que se viviera esta vida terrenal iban a ser el pago a un inmortalidad del alma, llena de paz y cercana de la presencia de dios, la existencia de esta forma de pensar permitía a los humanos vivir sin afanes, hoy no tenemos la oportunidad de disfrutar espacios de ocio prolongados, porque existe la presión de que el tiempo es corto y si la muerte se acerca al menos se debe haber logrado los lineamientos básicos de la vida: estudiar, trabajar, casarse, tener hijos, nietos y bisnietos, y por último, morir.

El tiempo tiene hoy otra concepción, y desde un óptica economicista es visto como recurso, cualquier minuto usado en algo no programado representa una pérdida invaluable, por eso "una sociedad en que el simple transcurso del tiempo multiplica los ducados, en que el tiempo es oro, es natural que se lo mida y se lo mida minuciosamente" (Sabato, 2006, 30), siendo "muy pocas horas libres las que nos deja el trabajo. Apenas un rápido desayuno que solemos tomar pensando ya en los problemas de la oficina (...) nos estamos volviendo incapaces de detenernos ante una taza de café en la mañana (Sabato, 2000, 20).

Finalmente, la individualidad como tercer factor, es promotor del egoísmo y la despreocupación por el otro, existe olvido por la familia, lo que rompe los valores de comprensión del yo para con el otro. Ahora, cuando el humano comienza a creer que es el centro del universo, y que esta visión ha abierto sus ojos a la libertad, considera que todo lo que lo rodea es medio para sus fines, es preocupante observar cómo en el día a día, este factor se afianza en la juventud, cuando con la tecnología, se fortalece ese encerramiento en el yo y se disfruta más con una conversación virtual y cada vez menos con un encuentro personal. Casi nadie ve lo qué pasa alrededor, es decir, el ensimismamiento se apodera del individuo que agachada la cabeza y se concentra por completo en el movimiento ágil de sus dedos en un teclado o una pantalla de celular.

Al combinar los vicios asociados a los tres factores, surge el problema ambiental, el cual trae consigo culpabilidad por lo hecho y por las omisiones. El miedo a morir aparece, aunque se sabe que los individuos antes de fallecer deben haber logrado satisfacer sus necesidades, no sólo básicas sino de acumulación de riqueza, y así, la única forma que tiene el humano de lograr vivir a plenitud, es considerando que todo lo que lo rodea es un recurso utilizable, incluso quien esté a su lado, el mundo es la despensa, la cantera, el sumidero.

Bajo esta forma de ver la problemática ambiental, el culpable no es el sistema capitalista, es el pensamiento humano que lo generó, el sistema capitalista solo refuerza y mantiene los factores desencadenantes del olvido de la naturaleza y del otro.

Ahora bien, el tema no solo se puede quedar en la crisis de pensamiento social, con la economía también hay debate, puesto que la economía neoclásica piensa en decisiones racionales asociadas al uso de las libertades, lo que Adam Smith citado por Friedman $(1983,49)$ denomina como natural, es que, "se deja a todos, mientras no violen las leyes de la justicia, en libertad perfecta para buscar la consecución de sus propios intereses a su manera y entrar con su actividad y su capital en competencia con la actividad y el capital de los demás hombres o categorías sociales". Desde esta perspectiva teórica, el mercado asigna un precio a los factores, lo que compensa los impactos que el actuar individual causa a la naturaleza.

Surge la inquietud de si la ley es un límite inferior indicado, si está al servicio de las personas o si simplemente se circunscribe a los agentes que detentan el 
poder, beneficiando a unos pocos y desconociendo a las mayorías. Este es un primer cuestionamiento que permite repensar este tipo de racionalidad.

Ahora, la racionalidad económica promueve el progreso individual $e$ inicialmente esta promoción no debería ser juzgada, pero Mill $(2004,7)$ considera "la utilidad como la suprema apelación en las cuestiones éticas; pero la utilidad, en su más amplio sentido, fundada en los intereses permanentes del hombre como un ser progresivo".

Es desde la utilidad que el hombre define si un acto es bueno o no, por ejemplo, partiendo del egoísmo es posible afirmar que todo lo que no me sea útil para lograr mi fin puede ser considerado malo. Al parecer la naturaleza y el mismo hombre en la generalidad de actividades empresariales, solo son un instrumento más, desde una visión utilitarista, son usados para alcanzar un objetivo particular.

Un segundo cuestionamiento al tema, se deriva de tratar "(...) de individualizar los salarios y los aumentos y de medir la eficacia individual (...) El individuo es rey (... ) Es evidente el riesgo de un individualismo exacerbado donde todo se vuelve posible al margen de cualquier regla y cualquier moral" (Le Mouël, 1992, 47).

El modelo ha llevado a pensar que la racionalidad económica se convierte en la base para conseguir la felicidad en el humano, Weber citado por Habermas (1999, 382-384) resalta la predominancia de la acción racional - teleológica, aquella que fundamenta su acción para la consecución del éxito; dejando atrás la acción racional - axiológica donde prima el conjunto de valores independientemente del éxito; la racional - afectiva donde dominan la pasión y sentimientos de la gente y la racional - tradicional donde dominan las costumbres donde se ha crecido. Una negación de valores sociales comunitarios argumenta aún más el segundo cuestionamiento hecho a este tipo de racionalidad.

Si se aterrizan estas apreciaciones a la empresa, a las decisiones en éstas, se deduce que están fundamentadas en la racionalidad económica propia del modelo neoclásico, que alimenta al neoliberalismo y que ha promovido el logro de un objetivo especifico "maximizar el valor de la empresa" o al menos hacerlo sostenible en el tiempo. Esta racionalidad se concentra en el incremento de rentabilidades y en los flujos de caja como el fin empresarial, pero no reflexiona sobre los medios para conseguirlo, al parecer cualquier medio es válido, siempre y cuando, el inversionista reciba su parte, él se interesa solamente por la acumulación continua y favorable. De esta manera "la mentalidad del capitalismo moderno reúne, como un deber un fin en sí mismo, la búsqueda del beneficio y la renovación incesante del beneficio mediante una actividad capitalista continua, racional" (Marshall, 1982, 97). Así pues, la acumulación continúa en detrimento del otro, es lo que se considerará como el tercer argumento en contra de la racionalidad económica.

A partir de lo anterior, es lógico preguntarse: ¿Es necesario cambiar? ¿Qué es lo que hay que cambiar? Aunque la racionalidad económica neoclásica lleve a que se esté “(...) rindiendo tributo, en las más diversas formas y figuras iEl dios progreso y el dios éxito!, en lugar de transcendencia, prima la eficacia, en lugar de apertura, ganancia, prestigio, carrera y éxito a cualquier precio" (Küng, 1997, 364).

Estamos asistiendo a una crisis del conocimiento, la razón principal es la inconsciencia que nos acompaña en cada uno de nuestros actos y obviar el otro al tomar una decisión, somos una sociedad inconsciente, porque aquellos que tienen el poder han definido nuestra forma de pensar, y por ende, la educación que recibimos en su mayoría está enfocada a satisfacer ese poder, entendiendo "(...) que el acceso al conocimiento daría argumentos irrefutables contra los que obraban injustamente (...) Hoy el poder emplea el saber que poseen sus expertos como la justificación básica fundamental de sus actos injustos" (Ralston, 1995, 56).

"La racionalidad capitalista ha estado asociada a una racionalidad científica y tecnológica que busca incrementar la capacidad de certidumbre, predicción y control sobre la realidad, asegurando una eficacia creciente entre medios y fines" (Leff, 2004, 172), en la forma como se piensa ha predominado el carácter instrumentalista para controlar todos los posibles es- 
cenarios que puedan generar impactos negativos en los desempeños económicos propiciados por el modelo, la racionalidad dominante limita la posibilidad de debate y se basa en un conjunto de herramientas para que los procesos sean cada vez más eficientes, sin preguntarse sobre los desequilibrios que estos retos generan.

La racionalidad económica promueve el interés en el objetivo, más no en el proceso que lleva a ese objetivo. Sus argumentos más fuertes de permanencia parten de la demostración que la felicidad está directamente relacionada con el éxito de esta forma de pensar propia de la "supervivencia".

Por supuesto que es necesario cambiar, ya que desde la racionalidad económica, "no sólo se define como racional la conducta de los actores sociales, que se rigen por las motivaciones del mercado, por la ganancia y la utilidad, sino que se busca deslegitimar los modos de organización social guiado por otros valores" (Leff, 2009, 195). Es necesario despegarse del televisor, pensándose a sí mismo, reconociendo al otro, pasando de una racionalidad economista a una racionalidad ambiental, pero ¿qué significa esto?

"La supremacía de la racionalidad económica se desmorona ante la evidencia del desarrollo ambiental, la pobreza y la desigualdad social crecientes en el mundo que ha construido" (Leff, 2009, 227). La racionalidad ambiental tal como expone Valenzuela (2007, 5), "supone cambios en todos los aspectos atinentes a las relaciones humanas con su entorno, en ese concepto acertado de ambiente que toca no sólo lo físico $y$ ecológico, sino que sigue un enfoque sistémico y holístico tutelado por las teorías de la complejidad, a diferencia de los enfoques reduccionistas y lineales que guiaron a la racionalidad económica".

En la racionalidad ambiental cada uno de los actores de este mundo es reconocido, cada uno tiene una percepción sobre el medio ambiente y es a través del diálogo de saberes, a través de la acción comunicativa que permite construir una relación con el otro. Esa relación es la que permitirá actuar de una manera diferente, "el diálogo de saberes se establece dentro de una racionalidad ambiental que rompe el cerco de la racionalidad objetivante y se abre hacia la otredad; busca comprender al otro, negociar y alcanzar acuerdos con el otro" (Leff, s.f, 8).

La base de la racionalidad ambiental es comprender la complejidad ambiental, que más allá de interpretar lo complejo desde los planteamientos de Morin pretende reconocer la diversidad en una realidad, por eso "la complejidad ambiental genera lo inédito en el encuentro con lo Otro, en enlazamiento de seres diferentes y la diversificación de sus identidades. En la complejidad ambiental subyace una ontología y una ética opuestas a todo principio de homogeneidad, a todo conocimiento unitario, a todo pensamiento global y totalizador" (Leff, 2006, 5).

El desarrollo sostenible planteado desde la racionalidad económica no es el camino indicado para la acción empresarial, con el pretexto de responder a la problemática ambiental porque "La racionalidad económica resiste a su deconstrucción y monta un simulacro en el discurso de desarrollo sostenible, una estrategia de simulación, un juego falaz de perspectivas, que burla la percepción de las cosas y pervierte toda razón o acción en el mundo hacia un futuro sustentable" (Leff, 2009, 107).

Así, la racionalidad ambiental emerge entonces como esa fuente de reconocer al mundo en el otro, para entenderse a sí mismo, en esta ley mínima, la instrumentalización de la naturaleza y de lo humano y la acumulación continua en detrimento del otro no tiene aplicabilidad, y por ende, no tendrían fuerza los cuestionamientos al tipo de racionalidad que utilizamos para la toma de decisiones. Por esto, el lenguaje para la conversación en la búsqueda de un consenso toma importancia como fuente de racionalidad ambiental, y de allí se genera el cambio individual.

\section{Empresa responsable socialmente}

La empresa ha asumido una figura particular diferente a las personas que la constituyen, hemos entendido esto como la "persona jurídica" aquella que a la vez que tiene derechos también tiene deberes. Pero es claro que a la hora de exigir derechos las empresas son perfectos ejemplos de unión en pro de la lucha por lo que merecen, pero cuando se les exige el cumplimiento de deberes esta unión se desvanece 
por la dificultad de responsabilizar a un individuo en particular por la actuación de la empresa en general, es más podríamos llegar a afirmar que la empresa es una persona inconsciente ante la variedad de posiciones sobre el mundo que en ellas se enmarca.

La salida para que una empresa, a la vez de asumir con fuerza la defensa de sus derechos también se responsabilice de sus deberes, está en el diálogo, pero de igual manera que la sustentabilidad y la racionalidad ambiental cuestionan el modelo económico dominante, el diálogo no es bien visto por esta corriente, Mill $(2004,6)$ cuestiona la posibilidad de pensar que la sociedad tras un diálogo pueda determinar lo acertado o lo justo, al afirmar que "Nadie puede ser obligado justificadamente a realizar o no determinados actos, porque eso fuera mejor para él, porque le haría feliz, porque, en opinión de los demás, hacerlo sería más acertado o más justo". Esto revela una posición individualista y una negación de la dependencia que siempre el hombre tiene de la sociedad, en este caso, el diálogo, y por consiguiente, el consenso al que podría llegarse no sería relevante.

Así como ya se ha planteado anteriormente, hay una instrumentalización organizacional del humano por el humano, ya que "en el mundo real moderno y contemporáneo de las organizaciones productivas, donde ha dominado y domina el principio de la racionalidad productiva instrumental, racionalidad para la cual los seres humanos son medios en el camino del logro de los fines y el buen trato se convierte en un asunto propio de la táctica respecto del fin (Cruz, 2003, 18).

Pero estamos cuestionando la manera de pensar actual, consideramos que a través de la sustentabilidad la empresa reconoce las múltiples dimensiones a las que tendría que orientarse, las cuales evidentemente pasan y superan lo económico y a través de la racionalidad ambiental reconocemos el diálogo de saberes que permite el reconocimiento del otro y por ende el de nosotros mismos a través de la acción comunicativa como "la situación en la que los actores aceptan coordinar de modo interno sus planes y alcanzar sus objetivos, únicamente, a condición de que hay o se alcance mediante negociación un acuerdo sobre la situación y las consecuencias que cabe espe- rar" (Habermas, 2008, 138). Por tanto, al escuchar entiendo mi realidad, porque es a partir del lenguaje que entiendo el mundo, mi interacción con el otro permitirá entender la problemática ambiental desde todo lo que nos rodea.

Es el diálogo, es el reconocimiento del otro en las empresas lo que garantiza la responsabilidad social, "solo el que está facultado para pedir, transforma el mundo con su petición. Solo quien está autorizado para prometer, transforma el mundo con su promesa" (Zea, 2004, 34). Si escuchamos al otro y planteamos un consenso no solo los actos que realicemos en la empresa serán legítimos, sino que adicionalmente la actividad será sustentable.

El problema para la aplicación de estas reflexiones en la empresa, es que los modelos actuales de responsabilidad social basados en la coordinación de la estrategia empresarial con la necesidad social no implican ningún cambio en la forma cómo se desarrollan los negocios, y por ende, mucho menos en los impactos que puede generarse a la naturaleza. Se trata de visiones limitadas que tienden a un mismo resultado, ahora la propuesta es convertir la necesidad social en negocio para garantizar la sostenibilidad de la empresa, tal como sucede con la creación del valor compartido.

"Esta idea representa una nueva forma de entender a los clientes (...) resalta las inmensas necesidades de las personas a quienes hay que satisfacer, los enormes mercados nuevos por atender y los costos internos de las carencias sociales y comunitarias así como las ventajas competitivas disponibles para quienes las aborden (...) Necesitamos una forma más sofisticada de capitalismo, imbuida de un propósito social. Pero ese propósito debería emerger no de la caridad sino de una comprensión más profunda de la competencia y de la creación de valor económico" (Porter \& Kramer, 2011, 16-18).

Sin embargo, desde otras perspectivas se evidencia un ajuste a la propuesta aquí planteada, la reflexión de León $(2010,13)$ permite sintetizar "la responsabilidad social empresarial debe considerarse desde el enfoque de los stakeholders donde se reconoce al otro como parte de acción por los efectos que puede o que se le pueden causar, la vinculación de cada 
uno de estos grupos en las decisiones, garantizando un trabajo sinérgico que legitima y abre caminos para garantizar la sostenibilidad de la empresa".

La vinculación del diálogo a la organización debe hacer parte de un modelo de gestión, orientado a ver la responsabilidad social como un eje fundamental para definir las pautas para la acción organizacional, si bien hemos reclamado que la solución al problema radica en un cambio en la forma de pensar fruto de una revolución cultural, en las organizaciones tres nuevos principios podrían coordinar un avance hacia el objetivo deseado, estos son:

- Negación del interés de competencia en el mercado: Las estrategias de gestión han fundamentado como punto de ataque de las organizaciones la competencia, a partir de la búsqueda incesante de líderes en el mercado, se aplican una serie de tácticas que hacen que la organización se concentre en un entorno hostil que no deja tiempo para pensar en sus procesos de desarrollo autóctonos, sino que la estrategia se orienta al cómo atacar al otro.

Sin embargo, para poder empezar un proceso de cambio organizacional que permita la inclusión de la perspectiva humana en los términos aquí planteados en la toma de decisiones, el primer paso es concentrarse en la organización y en sus programas de desarrollo, que el centro de la estrategia este en la particularidad de lo que se quiere.

Esta propuesta no es reciente, Chan Kim \& Mauborgne $(2008,3)$ habían planteado algo similar desde otra perspectiva que denominaron el "océano azul" y a la competencia, el océano rojo para el cual "siempre será importante mantenerse a flote gracias a vencer a los rivales (...) Las compañías deben ir más allá de la competencia".

- Humanización de la organización: En las organizaciones se han concentrado en gestionar las actividades en busca de la efectividad, esto está inmerso por ejemplo, en la cadena de valor donde la organización es un conjunto de actividades vinculadas por eslabones, actividades primarias y de apoyo. Sin embargo no se le da la importancia a quien realiza el día a día de esta cadena, esto son las personas.

La humanización de la organización consiste en no pensar en las actividades para el éxito como actualmente sucede, "el ser humano aparece fundamentalmente como un ser abstracto, un objeto económico, un individuo sin afectos, sin historia y sin cultura; se inscribe en un proyecto instrumental que confiere todas las virtudes a una sola lógica: la lógica técnica" (Chanlat, 2002, 50).

La búsqueda del éxito no debe partir de la mejor configuración de las actividades, sino de la mejor relación con los trabajadores que realizan esas actividades y que son el corazón de la organización, de vez en cuando es bueno preguntarles a los trabajadores si se sienten bien con lo que hacen.

- Comunicación transversal y abierta: La comunicación en la organización ha estado enmarcada en la temporalidad, se ha adaptado a discursos triunfalistas o fatalistas según el entorno y se ha convertido en el tema más variable para los trabajadores cuando después de un discurso cargado de sentimiento, como oda al talento humano, de repente y en momento críticos las reestructuraciones hacen parte de una decisión estratégica, donde quien sufre es ese mismo talento humano enaltecido anteriormente.

Etkin (1993, 280) destaca que "en las organizaciones pueden encontrarse ambientes de comunicación opacos, criterios contradictorios y superposición en los roles asignados. Todo ello como una estrategia global en esas instituciones, por ejemplo para poner a prueba a sus integrantes o para mantener el control sobre sus acciones". En este sentido, la comunicación ha respondido al interés del momento.

Para el cambio propuesto, la comunicación debe ser transversal, que el operario pueda hablar con el directivo y contarle sus experiencias operativas sin necesidad de seguir una jerarquía que puede modificar el sentido de los aportes, y además ser una comunicación abierta donde la palabra sea valorada como la creación de realidades en la mente del escucha.

La comunicación que acá se reclama parte de entender que los principales componentes del proceso 
comunicativo ya no son emisor y receptor, sino que ahora ambos son tomadores de decisiones donde la comunicación desarrollada afectara las acciones futuras que realizaran. Es reconocer que el escucha es igual al quien emite el mensaje.

Desde de estos tres principios, las organizaciones pueden pensarse a sí mismas a partir del reconocimiento del aporte humano y de su necesidad de sentirse participe de los procesos de toma de decisiones, de tal manera que el alineamiento a la estrategia no se dé por necesidad sino por legitimidad, esta forma de ver la organización desinstrumentaliza el humano abriendo paso para la construcción de realidades organizacionales que involucren un continuo diálogo de saberes.

\section{Reflexiones finales}

La deconstrucción de la forma como se ha venido actuando no puede venir de un proceso académico plasmado en documentos para la lectura, no basta con escribir, no basta con creer que somos conscientes de los problemas que actualmente vienen deteriorando la relación del humano con el ambiente, es necesaria la revolución cultural, y por ende, dejar atrás el miedo al cambio, en palabras de Leff (2004, 178) "la racionalidad capitalista no se combate tan sólo con los valores de una nueva ecosofia (...) requiere la construcción de otra racionalidad social".

Más que una sección de conclusiones este apartado deja una serie de cuestionamientos para nuestra reflexión, ya se observa cómo el reconocimiento del otro y el diálogo pueden constituirse en el fundamento del cambio necesario para pensar que es posible un mundo diferente basado en un cambio de racionalidad.

Quedan algunas preguntas por resolver: ¿Es posible el desarrollo sustentable, cuando los países desarrollados consumen más de lo que naturaleza puede recuperar? ¿Es posible pensar en un cambio de racionalidad en las condiciones actuales de nuestro país? ¿La empresa reconocerá al otro y buscará atender sus expectativas, equilibrando la variedad de objetivos?
Los debates semánticos e ideológicos con respecto del desarrollo sostenible y la sustentabilidad, distorsionan la aplicación de los mismos, bien sea en el ámbito de lo empresarial o en lo público; la invitación, es al diálogo entre los participes del desarrollo en aras de una construcción colectiva del mismo, que reconozca las particularidades de su entorno.

Por otra parte, el reconocimiento de la empresa como parte importante del desarrollo de la sociedad, lleva a elevarla también a la postura de principal agente de cambio en las rutas de la racionalidad ambiental propuesta; es la empresa la que al reconocer e interiorizar su influencia en el contexto social, natural y económico, puede responder al mismo y a la vez cambiarlo. Por consiguiente, cambios en la empresa podrían implicar cambios en los individuos que la componen.

Por eso, ir de la racionalidad económica a la racionalidad ambiental, implica un reconocimiento de lo individual, una diferenciación de lo humano dentro de la dinámica homogeneizadora que caracteriza la sociedad actual; este reconocimiento de lo particular se vislumbra como un gran reto, puesto que implica una revolución en el sentir - pensar - actuar de quienes habitamos el planeta.

\section{Referencias}

Alvarado, S. (2006). Metamorfosis de la concepción del cambio organizacional en el nuevo insitucionalismo. En: Revista Contaduría y Administración, 210: 11-40.

Ángel, A. (1996a). Desarrollo sustentable o cambio cultural una reflexión sobre el desarrollo agrario. En: Alvarez, J. et al. (eds.) La gallina de los huevos de oro: Debate sobre el concepto de desarrollo sostenible. Bogotá: Ecofondo - Cerec.

Ángel, A. (1996b). La fragilidad ambiental de la cultura. Bogotá. Editorial Universidad Nacional. Instituto de Estudios Ambientales IDEA.

Araujo, P. (2003) Nuevo institucionalismo, teoría de la estructuración y cambio en los sistemas y prácticas de contabilidad de gestión: teorías y métodos de investigación. En: Revista española de financiación y contabilidad, XXXII (118): 693-724.

Chan Kim, W. \& Mauborgne, R. (2008). La estrategia del océano azul. Editorial Norma. Bogotá

Chanlat, J. (2002) Ciencias sociales y administración. Fondo Editorial Universidad EAFIT. Medellín

Cruz, F. (2000) Hacia una redefinición del concepto de organización. En: Galvis, H. De lo humano organizacional. Santiago de Cali: Facultad de Ciencias de la Administración, Universidad del Valle. 
Cruz, F (2003). El lado inhumano de las organizaciones. Facultad de Ciencias de la Administración. Universidad del Valle. Cali

Elizalde, A (2007). Desarrollo humano y ética para la sustentabilidad. $2^{\mathrm{a}}$ edición. Universidad Bolivariana - ONU - PNUMA - Universidad de Antioquia.

Etkin, J (1993). La doble moral de las organizaciones. Mc Graw Hill. Madrid.

Etkin, J. \& Schvarstein, L. (1995) Identidad de las Organizaciones. Buenos Aires: Editorial Paidós, Primera Edición.

Friedman, M. (1983). Libertad de Elegir. Barcelona. Orbis.

Galeano, M. (2004). Diseño de proyectos en la investigación cualitativa. Fondo editorial Universidad EAFIT, Medellin.

Gallopin, G. (2003). Sostenibilidad y desarrollo sostenible: un enfoque sistémico. Extraído desde: http://www.infoagro.net/shared/ docs/a6/sosteniblilidad\%20y\%20desarrollo\%20sostenible.pdf

Gligo, N. (2006). Estilos de desarrollo y medio ambiente en América Latina, un cuarto de siglo después. Extraído desde: http://www. eclac.org/publicaciones/xml/9/28199/LCL2639-P.pdf

Gummenson, E. (2000). Qualitative Methods in Management Research. $2^{\text {nd }}$ edition. Thousand Oaks, CA: Sage.

Habermas, J. (1999). Teoría de la acción comunicativa: complementos y estudios previos. Red editorial iberoamericana, México.

Habermas, J. (2008). Conciencia moral y acción comunicativa. Editorial Trotta, Madrid.

Herrero, H. (2005). Los paradigmas de la sostenibilidad ¿Hacia una revolución ética y solidaria? Memorias IV Encuentro Iberoamericano de Periodismo Científico: Ciencia y Medio Ambiente, Guayaquil - Ecuador.

Jonás, H. (1994). El principio de la responsabilidad. Editorial Herder, Barcelona.

Küng, H. (1997). Una ética mundial para la economía y la política. Fondo de Cultura Económica, México.

Le Mouël, J. (1992). Critica de la eficacia. Ediciones Paidos, Barcelona

Leff, E. (s.f). Racionalidad ambiental y diálogo de saberes: sentidos y senderos de un futuro sustentable. Extraído el 31 de Octubre de 2009 desde: ojs.c3sl.ufpr.br/ojs2/index.php/made/article/ download/3042/2433

Leff, E. (2004). Saber ambiental. Sustentabilidad, racionalidad, complejidad, poder. Cuarta Edición. Siglo XXI Editores, México.

Leff, E. (2006). La Complejidad Ambiental. Extraído el 01 de Noviembre de 2009 desde: www.revistapolis.cl/polis\%20 final/16/doc/leff.doc

Leff, E. (2009). Racionalidad ambiental: la reapropiación social de la naturaleza. Siglo XXI Editores, Buenos Aires.

León, J. (2010). Responsabilidad social empresarial y cadena de valor: Reconstrucción de conceptos para una gestión más humana. Memorias CLADEA 2010. Extraído el 20 de abril de 2012 desde: http://www.ascolfa.edu.co/cladea2010/memorias_cladea2010/index.html

Lovelock, J. (1991). Gaia: una ciencia para curar el planeta. OASIS, Barcelona.

Márquez, G. (2002) Ecología y cultura: cambio ambiental, evolución biológica y evolución cultural. En: Politeia, 28: 41-56.

Marshall, G. (1982). En busca del espíritu del capitalismo. Fondo de Cultura Económica, México.

Mill, J. (2004). Sobre la libertad. Extraído el 23 de Octubre de 2009 desde: http://www.pensamientopenal.com.ar/15062007/mill.pdf

Montealegre, J. (2006) Relaciones entre la cultura organizacional y la resistencia al cambio: caso medianas y grandes empresas de confecciones de la ciudad de Ibagué. Tesis de grado no publicada. Manizales. Maestría en Administración Facultad de Ciencias y Administración. Universidad Nacional de Colombia.

Morgan, G. (1995). Imágenes de las organizaciones. Alfa Omega Grupo, México.

Porter, M. \& Kramer, M. (2011). La creación del valor compartido. En: Harvard Business Review, Enero 2011. Extraído el 15 de Junio de 2012 desde: http:/www.filantropiatransformadora.org/ attachments/article/198/Shared\%20Value\%20in\%20Spanish.pdf

Powell, W. \& Dimaggio, P. (2001). El Nuevo institucionalismo en el análisis organizacional. Fondo de Cultura Económica, México.

Ralston, J. (1995). La civilización inconsciente. Editorial Anagrama, Barcelona.

Rosas, J. (2008). El cambio en las universidades públicas estatales (UEPES) de 1982 a 2004. Estudio de caso: Universidad Juárez Autónoma de Tabasco. Tesis de grado no publicada. Querétaro. Doctorado en Administración, Facultad de Contaduría y Administración. Universidad Autónoma de Querétaro.

Sabato, E. (2000). La resistencia. Seix Barral, Buenos Aires.

Sabato, E. (2006). Hombres y engranajes. Grupo Editorial Planeta, Buenos Aires.

Uribe, A. (2005). Un examen semántico a las expresiones morales en Kant. Universidad del Rosario. Reportes de investigación, Nㅜ 60 .

Valdés, E. (208). Concepciones básicas sobre cambio organizacional. Extraído el 06 de mayo de 2012 desde: www.unipiloto.edu.co/ contenido/pdf relinter/admon/cambio.pdf

Valenzuela, L. (2007). Medio ambiente, empresa socialmente responsable y racionalidad Ambiental. Extraído el 10 de marzo de 2012 desde: www.spentamexico.org/revista/.../2(1)\%20 104-122_2007.pdf

Zea, L. (2004). La organización como tejido conversacional. Medellín. Fondo Editorial Universidad EAFIT. 